\title{
Los Ejercicios en la vida ordinaria del pueblo
}

\author{
Víctor Codina \\ Santa Cruz, Bolivia.
}

\section{Enfoque del tema}

Todos sabemos que la práctica de los Ejercicios Espirituales (EE) en toda la vida ordinaria, según la anotación $19^{\circ 1}$ de los Ejercicios de Ignacio de Loyola, ha abierto muchas posibilidades a la pastoral de los EE y ha permitido hacer los EE a muchos sectores que, por falta de tiempo y de posibilidades económicas, hasta ahora no habfan tenido acceso a los mismos².

Pero no voy a tratar directamente de cómo se pueden dar los EE en la vida ordinaria, según la anotación $19^{*}$, al pueblo sencillo, que es sin duda uno de los sectores que más se puede beneficiar de esa nueva praxis pastoral.

Tampoco voy a referime al tema de la importante presencia de la religiosidad popular en el texto ignaciano de los EE y a sus consecuencias pastorales. Lo doy por conocido ${ }^{3}$.

Voy a tratar de algo que es como más elemental pero, por lo mismo, más desaliante y paradojico. En el fondo, la idea surgí en el Congreso Internacional de Ejercicios, celebrado en Loyola en 19914. Su formulación en bruto, sin ulteriores matices, podrfa ser ésta: el pueblo sencillo, sin hacer los EE, vive muchas veces las grandes actitudes y experiencias de los EE. Dicho de otro modo, en una formulación impactante de Jon Sobrino en dicho Congreso de Loyola: 3,000 millones de personas de nuestro mundo "son puestos con el Hijo", sin haber hecho jamás el coloquio de las Banderas...

Mi propósito es sencillo, aunque un tanto ambicioso: señalar cómo en la vida ordinaria del pueblo, sin pretenderlo expresamente y sin formulaciones precisas, se van cumpliendo las diversas etapas del proceso de EE.

Indudablemente, esta afirmación se debería concretar más. Cuando hablo de pueblo me refiero al pueblo sencillo, a los sectores populares, pobres y ordina- 
riamente marginados de la sociedad. Concretamente, pienso en el pueblo de América Latina, de tradición cristiana, y más concretamente el de Bolivia, desde donde escribo, aunque creo que algunas de estas afirmaciones son extensibles a los sectores populares de otros países y de otros continentes.

Tampoco quiero magnificar al pueblo, haciéndolo, por el sólo hecho de serlo, portador mítico de la espiritualidad cristiana, en una especie de trasposición mesiánica y eclesiástica del proletariado marxista. Sabemos que el pueblo tiene, como todos los mortales, sus propios defectos, sus vicios y pecados. Sólo deseo descubrir en medio de eslas impurezas reales la rica veta espiritual que muchas veces se oculta. Indudablemente todo lo que diremos es mucho más verdadero con cuanta mayor profundidad el pueblo viva su fe cristiana. Muchas de las experiencias que luego describiré las he captado del contacto con comunidades cristianas de base.

No pretendo con ello desvalorizar la práctica de los Ejercicios, ni tampoco sacar conclusiones prematuras. En un primer momento me limitare simplemente a constatar y describir el hecho, aunque sea a grandes trazos y con pinceladas gruesas, para luego reflexionar sobre ello.

Sin duda, algunas afirmaciones podrán parecer demasiado genéricas o tal vez incluso exageradas. No es éste un trabajo de sociología religiosa, ni de antropología cultural, sino una aproximación espiritual, un acercamiento creyente al pueblo para poder escucharlo, un deseo de captar el mensaje de parte de aqueIlos a quienes han sido revelados los misterios del reino (Lc 10, 21; Mt 11, 25).

Huelga decir que cuando hablamos de las elapas de los EE no presuponemos que el pueblo las viva de forma ordenada, siguiendo la cronología de las cuatro semanas ignacianas. Sino que, a lo largo de toda su vida, el pueblo va experimentando e interiorizando estas vivencias espirituales. Pero nosotros, para proceder de lo conocido a lo desconocido, seguiremos el itinerario de los EE.

\section{Principio y Fundamento}

Seguramente los sectores más sencillos apenas entenderían el Principio y Fundamento ignaciano en su versión actual (EE 23). Y sin embargo viven muchas de las actitudes que el Principio y Fundamente presupone:

- una referencia constante a Dios, expresada de formas muy sencillas, desde el santiguarse al salir a la calle y cada vez que pasan por delante de una iglesia, hasta el empleo de expresiones donde se concentra el meollo del Principio y Fundamento: "Si Dios quiere", "Dios primero", "Dios mediante", "alabado sea Dios", "Dios sabe que no miento", "con la ayuda de Dios", "a Dios gracias", "¿por qué me ha sucedido esto, Dios mío?".

- esta referencia a Dios no sólo jalona el día, sino toda la vida del pueblo: 
nacimiento, madurez, trabajo, matrimonio, vida familiar, fiesta, enfermedad, muerte; Dios preside toda su vida, en una presencia viva, cálida y acompañante a lo largo de su vida, es el Dios de su vida y de la vida, sobre todo en el pueblo ligado a las culturas más originarias 5 .

- en todos los momentos, aun en los más duros y conflictivos, el pueblo no desespera, no blasfema, no reniega, se siente en manos de Dios, confra en su bondad y providencia, se sabe conducido por El, "aunque pase por quebradas muy oscuras" (Sal 23,4) de enfermedad, de falta de trabajo, de sufrimiento imprevisto, de muerte; no negamos que esta actitud a veces pueda conducir a cierta resignación pasiva, pero otras muchas está nutrida de una verdadera "indjferencia" ignaciana ante salud o enfermedad, vida larga o vida corta, pobreza o riqueza... (EE 23).

- llama la atención la constante actitud de acción de gracias y de alabanza al Señor del pueblo sencillo, que contrasta con la postura más pedigüeña de otros grupos sociales y eclesiales; precisamente porque el pueblo siente su vida amenazada, el poder llegar al final del dra le parece un milagro de Dios: el pueblo da gracias a Dios de cada día, del trabajo, del pan, de la salud, de la vida, de la familia, de poder alabarlo, de la comunidad cristiana... Su vida es como la tinaja de harina y la alcuza de aceite de la viuda de Sarepta, que sólo alcanza para el día (1 $\operatorname{Re} 17,7-16)$.

- esta alabanza, sobre todo en algunos sectores del pueblo ligados a culturas originarias, tiene una fuerte dimensión cósmica y telúrica: gracias a la tierra-madre por sus frutos, al agua y al sol, a las flores y al agua... 6 .

- a través de todo ello hay una fuerte percepción de que la vida es un don sagrado de Dios, que hay que defender y conservar, por el que hay que luchar; el tema de Ireneo sobre la vida humana como expresión de la gloria de Dios, está como muy presente en el pueblo.

Se ha dicho que el Principio y Fundamento nos coloca en una situación limite, en el punto cero de la existencia, donde nos encontraremos solos frente a nosotros mismos y ante el Señor. Pues bien, el pueblo vive ordinariamente en esta situación límite, al borde de la existencia, entre la vida y la muerte. Por esto no es extraño que experimente de forma ordinaria muchas de estas actitudes fundamentales. Su vida cotidiana le hace vivir con frecuencia estas experiencias fundantes que nosotros postulamos en la meditación del Principio y Fundamento.

\section{Primera semana}

No vamos a recorrer uno por uno todos los ejercicios de la Primera semana para mostrar cómo el pueblo los vive, sino recoger algunas de las actitudes más úpicas de esta etapa. 
Ya hemos dichos que no se podía mitificar al pueblo. El pueblo es pecador, cae con frecuencia en graves pecados: infidelidades, violencia, abusos, borracheras, corrupción, divisiones, odios...

Precisamente por esto el pueblo tiene conciencia de su propio pecado, se siente pecador, hace suyos los sentimientos del publicano de la parábola evangélica (LC 18,9-4). Su actitud rara vez es la del fariseo. Se siente indigno, no se atreve a comulgar sin previa confesión, pues está convencido que la eucaristía requiere una pureza de vida que él no posee.

A veces este sentimiento de su propia culpa va unido al miedo al castigo, con un temor tal vez poco filial. Pero tampoco es ajeno al sentido de misericordia y cree que en última instancia el Señor, que es bueno, le perdonará.

También para el pueblo sencillo, la figura de María, como para Ignacio y para los EE (EE 63), actúa como intercesora y mediadora, madre de bondad y misericordia, ante Cristo, el justo juez. Seguramente para muchos Marfa representa el rostro materno de Dios, quizás como consecuencia de una evangelización deficiente, que ofreció una imagen de Dios ligada al juicio y al castigo?.

Otras veces, el pueblo se siente movido a pedir perdón a través de ritos penitenciales populares, más sensibles y ligados a su cultura. La ceniza del comienzo de cuaresma es un rito penitencial bien popular, que nadie olvida'. También en las culturas originarias existen ritos de penitencia: subir a los cerros llevando pesadas piedras que simbolizan los pecados, que son lanzados luego al llegar a la cumbre. O sacrificios de llamas, que recuerdan el sacrificio del cordero pascual. Otras veces existen ritos comunitarios de reconciliación, por ejemplo en el matrimonio, donde las familias y grupos se piden perdón y se perdonan mutuamente. En algunas ocasiones, por ejemplo en semana santa, realizan penitencias por sus pecados, cargan pesadas cruces, arrastran cadenas, caminan descalzos...

De alguna manera, el pueblo intuye que el pecado tiene un efecto pernicioso que va más allá de la persona y contamina la sociedad. Por esto en muchas comunidades campesinas, ante una enfermedad o una sequia, la primera pregunta es saber quién ha pecado. Y algunos sectores más conscientes se dan cuenta que su pobreza y opresión no es querida por Dios, sino consecuencia del pecado social o estructural, contra el que hay que luchar.

El pueblo nada sabe del coloquio de misericordia ante el crucificado (EE 53), ni de los tres coloquios de la repetición de los pecados (EE 63). Pero vive en continua actitud de vergüenza y confusión por sus muchos pecados (EE 48), de arrepentimiento (EE 55), de gratitud por haber sido dejado en vida y no haber sido castigado por Dios (EE 60). 


\section{Segunda semana}

El pueblo no sabe mucho del reino de Dios, ni de la llamada del rey eternal, ni de la oblación de mayor estima y momento (EE 97). Pero intuye que Dios quiere un mundo mejor, donde haya justicia y fraternidad entre todos. Su lucha por la vida, por el trabajo, por una vivienda digna, por la salud y la educación, por los derechos humanos, es una lucha por los valores del reino. La solidaridad y el sentimiento de comunidad son valores del reino, profundamente arraigados en el pueblo. Muchas de sus actitudes no están lejos del reino de Díos.

Hay grupos cristianos que empiezan a leer la Palabra de Dios y comienzan a saborear el evangelio, a veces a pesar de su poca facilidad de lectura. A través de esta lectura popular de la Biblia, van adquiriendo conocimiento interno, amor y deseos de seguir al Señor (EE 104) en su vida de cada día.

Pero para la gran mayoría del pueblo, el conocimiento y seguimiento del Señor encarnado se realiza a lo largo de las fiestas de los misterios de la vida de Cristo que la Iglesia celebra cada año, como ya notó santo Tomás?.

Por navidad el pueblo canta villancicos, baila, adora al Niño, hace sus pesebres, escenifica la búsqueda de posada por José y María (las posadas mexicanas), celebra su novena con oraciones especiales incluso en la calle y en los comercios, reparte chocolate y juguetes a los niños, visita a los ancianos, se reúne en familia... En Bolivia, al comenzar la navidad, las familias llevan la imagen del Niño a la Iglesia, para que, después de haber recibido la bendición, sea venerada en la casa durante las fiestas de navidad. Por reyes, otra vez llevan la imagen al templo, antes de guardarla hasta el año siguiente. Nadie les obliga a ello, el pueblo recuerda cada año lo que debe hacer para cumplir su tradición.

A pesar de todo el impacto del consumismo moderno, el pueblo pobre es el que más se alegra por navidad, intuyendo que aunque los ricos de este mundo hayan intentado secuestrar esta fiesta, navidad es la fiesta de los pequeños y pobres. Un poema de un niño de una comunidad campesina de Puno, Perú, expresa bien esta relación entre navidad y los pobres:

Ha nacido el niño ya hay alegría porque ha nacido, todo cambiará
A la luz ya salen lodas las personas presos y enfermos y no sufrirán. 


\author{
Ya serán unidos \\ todos los hermanos \\ ni el costo de vida \\ ya nos matará. \\ El lobo ya no come \\ a la ovejita \\ ni la culebra pica \\ en todo el mundo hay paz. \\ De un tronco seco \\ saldrá una rama \\ y también nosotros \\ damos frutos ya. \\ El niño ha nacido \\ Gloria a Jesús \\ ha nacido pobre \\ como una luz ${ }^{10}$.
}

Las fiestas de María en sus diversas advocaciones populares, con rostros y geografla propia, alimentan la devoción a la madre de Jesús. $Y$ aunque muchas veces se mezcla una actitud milagrera o supersticiosa, en muchos se mantiene una devoción sencilla y llena de confianza. A través de Marla, se perciben actitudes evangélicas como la fe, la entrega al Señor, la disponibilidad, la confianza, el servicio a los demás...

También las fiestas de los santos, de los patronos populares, tienen gran arraigo en la fe de los sencillos. A veces su jerarqura no coincide con la oficial: en algunos lugares san Silvestre o san Judas Tadeo ocupan un rango que no corresponde exactamente al de la liturgia. A través de los santos hay una cierta comprensión de las actitudes evangélicas del amor y seguimiento. Son el equivalente popular de las vidas de santos o de la Imitación de Cristo, que Ignacio recomienda para la Segunda semana de EE (EE 100).

El pueblo no sabe nada sobre las dos banderas (EE 136-147), ni sobre las tres maneras de humildad (EE 165-167). Sin embargo, ha sido elegido y recibjdo no sólo en pobreza espiritual, sino en pobreza actual, pasando toda suerte de oprobios y vituperios (EE 147). Hay una identificación ontológica y existencial con la bandera de Jesús, con su camino de pobreza y humillación, con el Cristo pobre (EE 167). Ha sido "puesto con el Hijo", en la fuerte expresión de la mística ignaciana.

Y esta elección, aunque la gran mayoría no lo sepa ni lo valore, no deja de 
producir frutos del reino de Dios, ya que el reino se anuncia a los pobres ( $L c 4$, 18; Lc 7, 22) y de los pobres es el reino (Mt 5, 3; Lc 6, 20). A los pobres y pequeños han sido revelados los misterios del reino (Lc 10, 21; Mt 11, 25).

¿En qué se traduce esta elección? ¿No parece estar en contradicción con tantos pecados del pueblo, con tanta ignorancia y ceguera?

EI pueblo no conoce las reglas ignacianas para discemir espíritus, ni las normas y métodos sobre las elecciones, sin embargo, el estar puesto con el Hijo, y haber sido recibido bajo su bandera le da una connaturalidad con los valores del reino mucho mayor que la de los poderosos y ricos de este mundo, por más que muchos de ellos tengan mayor formación religiosa y sean más practicantes.

Existe una sabiduría popular y una profunda intuición cristiana, que lleva a opciones importantes y a veces difíciles, que demuestran un gran sentido evangélico: acoger a niños sin familia en una familia ya numerosa, cuidar a enfermos y ancianos durante años con una dedicación sacrificada, recibir al que viene de fuera en busca de trabajo, compartir lo poco que se tiene con los más necesitados, organizarse para defender sus derechos, protestar ante injusticias, la solidaridad con los compañeros del trabajo, la organización popular, las ollas comunes, esconder al perseguido... Y sobre todo, la capacidad para resistir y aguantar.

No es exagerado decir que dentro del pueblo, las más pobres, las más humilladas y sufridas son las mujeres. Pero ellas son muchas veces las que viven y encarnan de forma más fuerte los valores evangélicos. ¿No sucedió algo semejante con las mujeres de Israel?

Desde esta postura existencial de configuración con la bandera de Jesús, el evangelio se comprende mejor, hay una simpatía y empatía con la vida de Jesús, de María y de los santos, se vive una crítica permanente de la bandera de Lucifer en cuanto se experimentan sus efectos negativos en su propia came.

No queremos negar con ello que haya mucha gente del pueblo que tenga introyectada la bandera del mal caudillo y aspire a sus valores: tener, poseer, figurar, triunfar en la vida, disfrutar en la vida. O que viva la Bandera de Jesús con una resignación que nada tiene de cristiano. Pero es innegable que el pueblo nos sorprende continuamente con unas actitudes de gran profundidad evangélica.

Quisiera acabar este apartado con una anécdota reciente ocurrida en una comunidad de base. Leíamos y comentábamos la parábola de Lucas 10, 5-13 sobre el hombre que está en su casa ya acostado con sus hijos y recibe la llamada, a medianoche, de un amigo que le pide ayuda; al final se levanta a abrirle para que no lo siga molestando.

Un hombre de la comunidad dijo que él no comprendía esta parábola, porque si él estuviera en su casa y alguien lo llamase, aunque fuera a medianoche y 
estuviera ya en la cama, se levantarfa en seguida a abrirle para atenderlo...

\section{Tercera semana}

Si hay una semana que el pueblo vive de forma continua es la tercera semana. El pueblo está, permanentemente, en tiempo de pasión.

No pide dolor con Cristo doloroso, ni quebranto con Cristo quebrantado (EE 203), ni considera cómo la divinidad se esconde (EE 196). El vive en su propia carne la pasión del Señor y el silencio de Dios.

Basta acercarse al pueblo latinoamericano para contemplar su pasion. Sufrimientos físicos y morales, hambre, desnutrición, falta de vivienda digna, falta de agua y servicios higiénicos, falta de trabajo, falta de atención médica y sanitaria en sus enfermedades, despido, marginación social por su color y su cultura, humillaciones continuas, violaciones de sus derechos humanos, sufrimientos de la prepotencia de los poderosos, abusos de los agentes de orden público, atropellos, apresamientos en los gobiemos de facto, maltratos en las celdas policiales, torturas, asesinatos, falta de justicia en sus juicios... Tanto en el Documento de Puebla (31-39) como el de Santo Domingo (178-179) nos describen los rostros humillados de niños, ancianos, jóvenes, campesinos, indígenas, ...en los cuales se hace presente el crucificado.

Es el misterio del Siervo de Yahvé que sufre. El pueblo es este Siervo que crece sin belleza, como un leproso, humillado, despreciado, varón de dolores, triturado, que carga con nuestro pecado, como oveja al matadero, por cuyas cicatrices nos sanamos (Is 53, 1-6). Este siervo que al final no habla ni profetiza, sino que calla, sufre, aguanta, enmudece, y sin embargo, ilumina y tiene futuro (Is 53, 7-12)".

Existe una reflexión latinoamericana sobre el Siervo de Yahvé identificado con el pueblo pobre que sufre ${ }^{12}$.

Pero esta identificación del pueblo con el Cristo paciente ha llegado en América Latina a su punto álgido en el martirio. El pueblo no sólo sufre, sino que es crucificado, martirizado. Ellacuría escribió sobre el pueblo crucificado ${ }^{13}$ y le tocó luego a él participar del misterio de la muerte de Jesús. La teología de la liberación se ha convertido en una teología del martirio ${ }^{14}$.

Muchos de estos mártires no son mártires de la Iglesia, ni han muerto por defender sus dogmas (la eucaristía, el primado de Pedro...), sino que son mártires del pueblo, mártires de la humanidad, del reino, mártires muchas veces pasivos, en una santidad primera y elemental, como lo pudo ser la de los mártires inocentes que murieron asesinados por Herodes's.

Es la consecuencia lógica y evangélica de haber sido puestos con el Hijo, es el precio de la identificación ontológica y existencial con Cristo pobre: persecu- 
ción, atropello, martirio.

El pueblo vive todo esto de forma más refleja en las fiestas de la cruz y sobre todo en cuaresma, asistiendo al via crucis, llevando la cruz, tomando parte de las procesiones de semana santa, subiendo a los calvarios, contemplando en silencio y con gran devoción la ceremonia de la "desclavada" o desclavamiento y descendimiento de la cruz que en muchos lugares se representa el viernes santo $^{16}$.

A veces, quienes no sufrimos como el pueblo, podemos tener la impresion de que el pueblo ha hecho de la cruz el centro de su vida y que no ha llegado a la fe pascual. Indudablemente esta postura a veces puede derivar en resignación pasiva, dolorismo masoquista. Pero ordinariamente el pueblo no acude a la cruz para quedarse en ella, sino para poder vencerla y superarla, para poder sobrevivir.

El pueblo acude a la cruz para cobrar fuerza para soportar su propia cruz y las "pasividades".

La tercera semana en los EE confirma y da fuerza para llevar adelante la elección. El pueblo recibe fuerza en su tercera semana de pasión para poder seguir adelante en el lugar donde el Señor lo ha puesto y lo ha elegido.

Y misteriosamente, este pueblo pobre, sencillo, pecador, que sufre sin culpa los pecados de los otros, nuestros pecados, se ha convertido, como el Siervo de Yahvé, en fuente de luz y de salvación para toda la humanidad.

La Virgen dolorosa, acompaña al pueblo en su dolor y el pueblo acompaña a la dolorosa en los pasos de su pasión. Las mujeres del pueblo, como la Dolorosa, aguantan y luchan, hasta la heroicidad: huelgas de hambre de mujeres mineras, marchas de mujeres embarazadas en defensa de sus tierras, mujeres indígenas que se organizan aun sabiendo que corren peligro... La figura de Rigoberta Menchú puede ser un símbolo de estas sufridas mujeres del pueblo ${ }^{17}$.

\section{Cuarta semane}

Parecerfa que el pueblo vive tan intensamente la tercera semana que no llega a la cuarla. Parece que permanece en los infiemos de la soledad y la muerte y que no sale de ellos.

Ciertamente que no pide alegría y gozo de tanta alegría y gozo del Señor resucitado (EE 221). Sin embargo, el pueblo intuye que la cruz no es la última palabra, ni que el verdugo vence definitivamente sobre la víctima. Hay una fe firme, que espera contra toda esperanza. Siempre sueña un mañana mejor, espera que Dios no le va a abandonar, no le puede abandonar, un día triunfará finalmente la justicia de Dios. 
Es en sus fiestas donde el pueblo vive el gozo pascual, la victoria de la justicia sobre la injusticia, de la vida sobre la muerte. Sus fiestas son un anticipo la utopla del reino.

En la fiesta hay abundancia, compartir, gozo, color, música y baile, crílica implícita de la sociedad actual, donde sólo reina la mentira y la desigualdad. La fiesta es una señal de la tierra sin males a la cual camina en medio de tanto dolor.

Seguramente la dimensión más estrictamente pascual, eclesial y sacramental permanece muchas veces poco explicitada, muy latente, pero no está ausente. De esta fuente última el pueblo saca fuerza, paciencia, esperanza. Sin saberlo, recibe la luz y la seguridad de que está en el lugar jusıo, con los de abajo, no con los vencedores de turno, que oprimen a sus hermanos.

Esta alegría pascual se manifiesta en forma de comunidad solidaria también con los muertos, en forma de comunión de los santos. $\mathrm{Y}$ en las celebraciones sacramentales de los sacramentos de las cuatro estaciones de la vida (bautismo, primera comunión, matrimonio, entierro), el pueblo participa del misterio pascual y vive su pertenencia eclesial. Sin saber nada de las reglas para sentir con y en la Iglesia (EE 532-370), el pueblo respeta al Papa, a sus obispos, a los sacerdotes y religiosas, llamadas cariñosamente "madrecitas".

Ciertamente el Esplritu acompaña el caminar del pueblo en todo este recorrido vital. $Y$ sin conocer nada de la contemplación para alcanzar amor (EE 321-237) ni de los tres modos de orar (EE 238-260), el pueblo, que intuye que el amor se ha de poner más en las obras que en las palabras (EE 230), reza, encuentra con facilidad a Dios en la vida de cada día y vive agradecido y confiado en Dios, esperando siempre un mañana mejor para sus hijos. La virtud de la esperanza, la más pequeña de las virtudes teologales, pero la que más agrada a Dios, según Péguy, no le falta ciertamente al pueblo. Sólo de la resurrección del Señor puede brotar esta alegrla y confianza.

\section{Reflexiones finales}

¿Qué lecciones podemos sacar de todo lo expuesto hasta ahora?

1. En primer lugar, no puede extrañar que haya convergencia entre la vida cristiana del pueblo sencillo y el proceso de los EE, dado que éstos son como un concentrado de la vida cristiana, siguiendo el camino del Jesús histórico hacia la pascua. Lo novedoso estriba en la toma de conciencia de esta realidad.

2. Se ha dicho que la Anotación $19^{\circ}$ confiere a los EE un tono de realismo por su confrontación cotidiana con la vida ordinaria, que evita el riesgo de irrealidad, siempre posible en una experiencia espiritual al margen de la vida cotidiana. Los EE vividos en la vida ordinaria por el pueblo, también dan a 
aquéllos un toque de realismo y veracidad.

3. Asombra constalar la riqueza de la vida cristiana del pueblo pobre, fruto sin duda de la connaturalidad entre los pobres y los valores del reino. La identificación ontológica y existencial entre los pobres y el Jesús histórico confiere a su vida una densidad evangélica especial, al margen de sus limitaciones morales personales. El pobre continúa siendo un lugar teol6gico y espiritual privilegiado para vivir y captar el evangelio del reino. La bienaventuranza bíblica de los pobres continúa teniendo vigencia. Los pobres son punto de referencia obligado para la vida y la espiritualidad cristiana y un criterio para todo discernimiento cristiano.

Esta riqueza de la vida cristiana del pueblo contrasta muchas veces con la mediocridad de tantos cristianos no populares que hacemos los EE con frecuencia y no pasamos más allá de buenos deseos, ni logramos realmente que los valores del reino impregnen nuestra vida personal y social.

4. Existe una clara prioridad de la vida, de la historia, de la realidad sobre el texto, la reflexión, el método, el ejercicio y la teoría. En la formulación de $\mathrm{C}$. Mesters, el "pre-texto" (la vida) antecede al mismo "texto". Esto obliga a desmitificar los mismos EE y a asumirlos con modestia, con conciencia de sus límites y con honradez.

Sería ridículo pensar que sólo los que han tenido acceso a una formación, reflexión y experimentación sistemática sobre la vida espiritual puedan llegar a la plenitud de esta vida. Es necesario hacer una crítica contra toda forma de elitismo espiritual. La vida ordinaria del pueblo nos prohíbe asf cualquier absolutización de métodos, escuelas e instrumentos de espiritualidad. Los últimos son los primeros, las prostitutas y publicanos anteceden a los fariseos en el reino (Mt 21, 28-32).

5. Esto no significa que los EE sean inútiles y que no puedan ayudarnos a todos a profundizar, purificar y clarificar muchas de las vivencias espirituales cristianas. Los EE pueden ser un buen instrumento para todo ello.

También para el pueblo cristiano sencillo, los EE pueden ser una gran ayuda para poder vivir la "pobreza con Espíritu". Las continuas ambigüedades que hemos ido señalando en la vida del pueblo, necesitan de una continua clarificación. Sin un proceso de personalización y profundización personal, el mismo pueblo degenera en un mito abstracto y colectivo.

En este sentido, los EE, según la anotación 19*, pueden ser un medio privilegiado para que el pueblo sencillo, sin dejar su trabajo, ni su familia, pueda profundizar su experiencia del misterio pascual, aprenda a discernir los signos de los tiempos y halle la voluntad de Dios.

También aquí, contra toda forma de elitismo aristócratico, hay que afirmar 
"que en los sectores populares se pueden hallar personas de mucho "subjecto" para hacer los EE y que, de hecho, muchos los hacen con gran fruto.

6. Por todo ello, si no queremos que los EE queden desvinculados de la acción del Espíritu, deberán referirse continuamente a la vida del pueblo. No sólo el pueblo es capaz de hacer los EE con profundidad, sino que el pueblo ayuda a su teorfa y a su praxis. Desde el pueblo pobre se comprende mejor la vida de Jesús y el sentido de la espirilualidad cristiana. La vida del pueblo anterior al texto de los EE, ayuda a la comprensión de los EE. El "pre-texto" no sólo antecede cronológicamente al "texto", sino que ayuda a comprenderlo mejor.

Por ejemplo, la tercera semana no podrá entenderse correctamente al margen de la pasión del pueblo: desde los crucificados se comprende mejor al crucificado, la historia ayuda a comprender la cristología. La primera semana no puede vivirse sin considerar las consecuencias del pecado personal y social que el pueblo sufre. El sentido de esperanza y de fiesta del pueblo ilumina la cuarta semana. La pobreza real del pueblo ayuda a comprender, sub contrario, qué es el reino y qué significa ser puestos con el Hijo bajo su bandera. Nuestra fe se ilumina desde la fe del pueblo, nuestra sabiduría carnal con su sabiduría humana y cristiana.

El pueblo da a los EE una densidad humana y cristiana que evita el riesgo de evasión espiritualista. En un mundo donde tres cuartas partes de la humanidad pasa hambre, las reglas para ordenarse en el comer (EE 210-217) o para distribuir limosnas (EE 337-344) deben ser profundamente reinterpretadas desde una perspectiva social nueva.

La elección, incluso la elección del estado de vida, puede hallar desde esta óptica una luz profunda. Toda la doctrina ignaciana del discernimiento se abre asf a una dimensión histórica y social, sin la cual el discemimiento quedaría enclaustrado en la pura subjetividad. En el fondo, la consolación no es sólo mi alegría y mi paz personal, sino todo aquello que lleve verdadera alegria al pueblo pobre y pequeño, es la alegría y la paz mesiánica anunciada por los ángeles a los pastores (LC 2, 8-18). El fruto último de los EE ha de ser, en última instancia, aumentar el gozo y la alegría del pueblo.

7. De este modo se cierra el círculo hermenéutico entre el texto y su interpretación, entre el pueblo y el texto de los EE. Ignacio reflejó en los EE sus experiencia de laico bautizado, de cristiano popular, aunque iluminada por sus gracias místicas personales de Loyola y Manresa. Del pueblo recibió Ignacio gran parte de su piedad. Es lógico ahora devolverle al pueblo lo que de él nació y enriquecerse con los aportes del pueblo de hoy. Hay una mutua circularidad: la vida del pueblo ayuda a comprender los EE y los EE ayudan al pueblo. Hay que devolver los $\mathrm{EE}$ al pueblo e integrar lo popular a los $\mathrm{EE}$. 
8. Si los Ejercicios se llaman espirituales es porque en ellos actúa el Espíritu, aunque Ignacio tema hablar del Espíritu por miedo a ser tenido por alumbrado o quietista. Pero el Espíritu no ha quedado cristalizado en un texto, sino que continúa actuando en la historia de la Iglesia y del mundo. Los EE son un texto "abierto". La hermenéulica del texto se ha de hacer a la luz del Espíritu, para lo cual el pueblo pobre es un lugar privilegiado. Del pueblo crucificado brota una luz que ilumina a todos. Asf, los EE desbordan el mundo eclesiástico e incluso eclesial y se abren a una historia donde el reino está presente de formas ocultas $y$ variadas.

Pedir ser puestos con el Hijo y ser recibidos bajo la bandera de Jesús, significa hoy pedir ser puestos con el pueblo pobre y crucificado. Para ayudarlo a bajar de la cruz. Para que tenga vida en abundancia $(\mathrm{Jn} 10,10)$.

\section{Notas}

1. La Anolación $19^{\circ}$ ofrece la posibilidad de hacer los EE en la vida ordinaria a los que no pueden retirarse ni desembararzarse totalmente de sus ocupaciones. Estos pueden seguir el mismo método y ritmo de los EE, alargando el proceso y dedicando una hora y media a la oración cada dia.

2. Remito a las obras, algunas de ellas ya clásicas, de G. Cusson, Los Ejercicios espiriruales en la vida corriente, Santander 1976; M. Guiliani, La experiencia de los Ejercicios Espirituales en la vida, Santander 1992; F. Riera, Ejercicios espirituoles en la vida ordinaria para comunidades de laicos, Santander 1990; J. M' Rambla, Ejercicios en la vida corriente, Barcelona 1991.

3. Remito a mi artículo, "La religiosidad popular en los Ejercicios de San Ignacio", Revista Latinoamericana de Teología, 10 (1987), pp. 89-90, que también apareció en Perspectiva teológica (Belo Horiżonte) $n^{\circ} 49.1987$ y en Christus (París) nº 158, 1993.

4. Cf J.M. García Lomas (Ed), Ejercicios Espirisuales y mundo de hoy. Congreso Internacional de Ejercicios, Loyola 20-26 septiembre 1991, Bilbao-Santander 1992.

5. M. Marzal (coordinador), El rosiro indio de Dios, Lima I991.

6. V. Codina, Teología simbólica de la vierra, colección CLAR, Bogotá 1993.

7. Cf V. Codina, "Credo popular y credo olicial Revisia Larinoamericana de Teología, 26 (1992), pp. 243-253.

8. Codina, "Sacramentales, sacramentos de los pobres", en Revista Latinoamericana de Teologia, 20 (1990), pp. 207-19.

9. De quibus ecclesia festa facil, De Verilate $q 14 \mathrm{a} / \mathrm{l}$.

10. D. Irarrázaval, "Navided en la tradición del pobre", en Rito y pensar cristiano, Lima 1993, p. 58.

11. Dolores Aleixandre, "Sus heridas nos curaron", Sal Terrae, 81 (1993) n 954, pp. 125-137. Todo el número está dedicado a este tema.

12. C. Mesters, La misión del pueblo que sufre, CLAR, Bogotá 1983; L. Boff, Pasión de Cristo, pasión del mundo, Bogotá 1978.

13. I. Ellacurfa, "El Pueblo crucificado. Ensayo de soteriologla histórica" en Varios, 
Cruz y resurrección, México 1978, pp. 49-82, retomado luego en Mysterium Liberationis, II, Madrid 1990, pp. 189-217.

14. J. Sobrino, "De una teologia de la liberación a una teologla del martirio", en Cambio social y pensamiento cristiano en América Latina, Madrid 1993, pp. 101-121.

15. J. Sobrino, 1. c., pp. 113-114.

16. F. Damen, E. Judd Zanon, Cristo crucificado en los pueblos de América Latina. Antología de la religión popular, Cusco-Quito, 1992.

17. V. Codina, Rigoberta Menchú: "Crucé la frontera", Cuorto Intermedio, Cochabamba, $n^{0} 28$, agosto 1993, pp.25-43. 